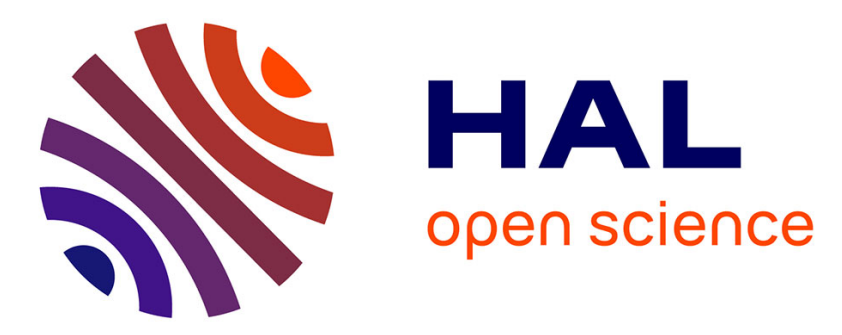

\title{
Mitochondrial Transport, Partitioning and Quality Control at the Heart of Cell Proliferation and Fate Acquisition
}

Rakesh Kumar Sharma, Abderrahman Chafik, Giulia Bertolin

\section{To cite this version:}

Rakesh Kumar Sharma, Abderrahman Chafik, Giulia Bertolin. Mitochondrial Transport, Partitioning and Quality Control at the Heart of Cell Proliferation and Fate Acquisition. 2021. hal-03383673

\section{HAL Id: hal-03383673}

https://hal-univ-rennes1.archives-ouvertes.fr/hal-03383673

Preprint submitted on 18 Oct 2021

HAL is a multi-disciplinary open access archive for the deposit and dissemination of scientific research documents, whether they are published or not. The documents may come from teaching and research institutions in France or abroad, or from public or private research centers.
L'archive ouverte pluridisciplinaire HAL, est destinée au dépôt et à la diffusion de documents scientifiques de niveau recherche, publiés ou non, émanant des établissements d'enseignement et de recherche français ou étrangers, des laboratoires publics ou privés.

\section{(c)(1)}

Distributed under a Creative Commons Attribution| 4.0 International License 


\title{
Mitochondrial transport, partitioning and quality control at the heart of cell proliferation and fate acquisition.
}

\author{
Rakesh Kumar Sharma ${ }^{1, *}$, Abderrahman Chafik $^{1,{ }^{*}}$ and Giulia Bertolin ${ }^{1}$ \\ ${ }^{1}$ Univ Rennes, CNRS, IGDR (Genetics and Development Institute of Rennes), UMR 6290, F-35000 \\ Rennes, France \\ ${ }^{*}$ These authors equally contributed to this work.
}

Correspondence should be addressed to GB: giulia.bertolin@univ-rennes1.fr; Tel: +330223237516

\begin{abstract}
Mitochondria are essential to cell homeostasis, and alterations in mitochondrial distribution, segregation or turnover have been linked to complex pathologies such as neurodegenerative diseases or cancer. Understanding how these functions are coordinated in specific cell types is a major challenge to discover how mitochondria globally shape cell functionality. In this review, we will first describe how mitochondrial transport and dynamics are regulated throughout the cell cycle in yeast and in mammals. Second, we will explore the functional consequences of mitochondrial transport and partitioning on cell proliferation, fate acquisition, stemness, and on the way cells adapt their metabolism. Last, we will focus on how mitochondrial clearance programs represent a further layer of complexity for cell differentiation, or in the maintenance of stemness. Defining how mitochondrial transport, dynamics and clearance are mutually orchestrated in specific cell types may help our understanding of how cells can transition from a physiological to a pathological state.
\end{abstract}




\section{Introduction}

Mitochondria are found in most of the eukaryotic cells and they contribute to many functions such as ATP generation, $\beta$ oxidation of fatty acids, and cellular metabolism (1). Mitochondria are also implicated, among other functions, in reactive oxygen species (ROS) generation and turnover, in apoptotic pathways, and in calcium signaling (1). Mitochondria are dynamic and motile organelles $(2,3)$ that constantly fragment (a mechanism also known as fission) and fuse $(3,4)$. Mitochondria also undergo turnover, which comprises selective clearance by mitophagy when organelles are damaged and biogenesis events to increase the mass of the mitochondrial network (4). Mitochondrial fission is driven by the binding of Dynamin-1-like protein (Drp1/DNM1L) to its receptor proteins MFF (mitochondrial fission factor), MID49/51, and/or FIS1 on the mitochondrial outer membrane $(4,5)$. Oligomerized DNM1L wraps around mitochondria by forming a ring that causes Outer Mitochondrial Membrane deformation and scission (6). Daughter mitochondria obtained after fission may undergo re-fusion with the rest of the network, or they can be subjected to mitophagy in case their activity is compromised, such as after the accumulation of deleterious mtDNA mutations, of ROS, or of misfolded proteins (7). In contrast to fission, mitochondrial fusion is a mechanism in which two mitochondria fuse together, and the two mitochondrial units share tRNAs, rRNAs, proteins and matrix metabolites (8). Fusion between Inner Mitochondrial Membranes is mediated by Optic Atrophy Protein 1 (OPA1), while on the Outer Mitochondrial Membranes (OMM) Mitofusin1 (MFN1), and Mitofusin2 (MFN2) are the key players (9). Mitochondrial fusion and fission processes are collectively known as mitochondrial dynamics and influence nearly all mitochondrial functions including respiration, calcium buffering, bioenergetic adaptation, and apoptosis $(10,11)$.

Here, we will review our current state of the art on how mitochondrial dynamics is involved in and required for the transport of mitochondria within the cell, and for the effective clearance of mitochondria under physiological conditions. We will also recapitulate our current knowledge on the consequences of mitochondrial transport, dynamics and mitophagy failures for mitochondrial homeostasis, cell stemness and fate acquisition.

\section{The interplay of mitochondrial transport and dynamics ensures faithful organelle distribution.}

Mitochondria move along the cytoskeleton with the help of the motor proteins and this function is critical for organelles to orchestrate fission, fusion and quality control events. In specialized cells as neurons, mitochondrial movements towards the axonal ends are critical for fulfilling the energy required at synapses. In mammals, mitochondrial movements occur on the microtubules with the help of motor proteins such as kinesins and dyneins $(12,13)$. The recruitment of the motor proteins on the mitochondrial surface is essential for mitochondrial transport. Typically, these motor proteins are opposite in nature, and the kinesins transport the mitochondria to the plus end of the microtubule (anterograde), while dynein to the minus end (retrograde). The adaptor proteins Milton/TRAK help in the anchoring of mitochondria by motor proteins, as they interact directly with the OMM proteins MIRO 1/2 on one hand, and 
with the cytoskeletal protein Kinesin 5 on the other hand (13). MIRO proteins also interact with the mitochondrial fusion proteins MFN1 and MFN2, thereby linking mitochondrial dynamics and transport $(12,14)$. This link is further corroborated by the observation that the motor protein dynein is critical for DNM1L-mediated fission (15). The disruption of dynein functions in HeLa cells dramatically changes the organization of the mitochondrial network and inhibits organelle fission, causing extensive branching and tubular mitochondria (15). However, what are the consequences on cell physiology, metabolism and proliferation if mitochondrial transport and dynamics are impaired?

\section{Mitochondrial transport and inheritance during cell cycle progression}

As introduced above, mitochondria play multiple functions and their proper distribution during cell division is essential for cell survival. However, these organelles can only be generated by an increase in mitochondrial mass, followed by the separation of pre-existing mitochondria from the network (16). Therefore, the maintenance of the mitochondrial pool must be coordinated throughout the cell cycle to ensure the proper distribution of these organelles in the daughter cells. Mutations in genes encoded by the mitochondrial genome are lethal in higher vertebrates, thereby limiting our capacity to explore how these mutations might affect mitochondrial inheritance. To overcome this issue, early studies on mitochondrial inheritance were performed in baker's yeast (Saccharomyces cerevisiae), and showed that organelle inheritance is well coordinated with the cell cycle.

Actin cables - bundles of F-actin acting as a track for the bidirectional movement of cargo are responsible for the transfer of mitochondria from the mother to the bud. In addition, these cables also arise from the bud tips and undergo continuous movements toward the mother cell tip. This backwards movement is called retrograde cable flow (RCAF) and as described below, increased RCAF rates for mitochondria are linked with the fitness of the mitochondria that are transferred to the bud. In the early stage of the $G_{1}$ phase, actin starts to polarize, and mitochondria align with the mother-bud axis. In the $S$ phase and until the $\mathrm{G}_{2}$ phase, mitochondrial movement occurs towards the bud tip by anterograde linear excursions, and towards the mother tip by retrograde linear excursions $(17,18)$. This bidirectional movement leads to the accumulation of mitochondria into both bud and mother cell tips in an actindependent manner. During the $M$ phase instead, mitochondria are shed from actin and distributed throughout the bud $(17,18)$. The mutant yeast strain tpm $1 \Delta$ lacking a functional actin stabilizing tropomyosin 1 gene (TPMI) shows abnormal mitochondrial distribution and morphology (17). Mutations in the actin-encoding gene ACT1 (19), or in the chaperoneencoding genes CCT4 and CCT6 which are essential for actin folding, cause defects in mitochondrial morphology and unequal distribution of mitochondria to the daughter cell (1921). During cell division, mitochondrial inheritance mechanisms ensure the transfer of metabolically active mitochondria to the daughter cell, while mitochondria with a highlyoxidized redox potential are retained in the mother cell and maintain the mother-daughter age asymmetry in yeast $(18,22)$. Deleting the Mmrlp protein, a member of the DSL1 family that assists the tethering of mitochondria to the bud, was shown to compromise the quality of mitochondria delivered to the daughter cell (22). Yeast Sirtuin (SIRT2) was also found to be 
essential for the normal RCAF and for mitochondrial inheritance during cell division. Any perturbation of its functions causes the transfer of mitochondria containing high reactive oxygen species to daughter cells and reduces yeast lifespan $(18,22,23)$.

Last, Altmann et al. showed that the class V myosin motor protein Myo2 is essential for actinmediated mitochondrial transport (24). They showed that Myo2 facilitates the binding of mitochondria to actin, and it helps mitochondrial motility during cell division. Moreover, mutations in $\mathrm{Myo} 2$ that alter the binding of mitochondria to actin cables cause the abnormal accumulation of mitochondria in the mother cell (24). Although a significant body of evidence illustrated that mitochondrial delivery and quality control in yeast is mediated by actin throughout the cell cycle, the majority of the molecular motors involved beyond Myo2 still remains to be discovered.

In mammalian cells, mitochondrial segregation also occurs during mitosis. However, a crosstalk between the mitochondrial dynamics and the cell cycle machinery begins as early as a cell commits to cell cycle entry $\left(\mathrm{G}_{0}-\mathrm{G}_{1}\right)$, and both cell cycle progression and mitochondrial division occur in parallel.

During the $G_{1}$ phase, the biosynthesis of the mitochondrial complexes occurs $(25,26)$. As the cell progresses towards the S phase, the levels of Cyclin E increase together with the Cyclin E-dependent inhibition of DNM1L $(27,28)$. This tips the mitochondrial dynamics balance towards fusion, and mitochondria appear as a hyper-fused and compact tubular network (27, 28), together with high ATP synthesis capabilities needed for the cell cycle to progress (29). During the S phase, mitochondrial DNA content also increases, thereby reflecting a strong coordination between nuclear and mitochondrial DNA synthesis processes (30). As the cell progresses toward mitosis, the levels of Cyclin B increase and the CDK1 (Cyclin-dependent kinase 1)/Cyclin B complex phosphorylates DNM1L on Ser585 (31) and on Ser616 (32). The phosphorylation of DNM1L is critical to activate its GTPase activity, leading to the activation of mitochondrial fission programs during cell division (33) (Fig. 1).

From the beginning of the $\mathrm{G}_{1}$ phase and until mitosis, mitochondria are associated with motor proteins for their transport. After fission at mitosis, mitochondria are released from microtubules upon the phosphorylation of dynein by CDK1, and of kinesin-1 (Kinesin Heavy Chain or KHC) by Aurora A/AURKA $(31,34,35)$. Interestingly, motor proteins were shown to be required for mitochondrial fission events during early mitosis. After fission is achieved, motor shedding is necessary for the symmetric distribution of mitochondria in mammalian cells (34). The forced attachment of kinesin to mitotic mitochondria causes an asymmetric mitochondrial distribution in the daughter cells, while the attachment of dynein-bound mitochondria to the mitotic spindle arrests cell at mitosis (34). This strongly supports the notion that the release of motor proteins from the mitochondrial membrane is crucial for successful progression through mitosis (Fig. 2). However, the mechanism of mitochondrial distribution after the release of motor proteins remains controversial $(12,34,36)$. Chung et al. showed that mitochondrial distribution occurs passively after the release of the motor proteins during mitosis, and treatment of cultured cells with the actin-depolymerizing agent latrunculin A did not alter mitochondrial partitioning into the two daughter cells (34). However, Moore et al showed that mitochondria were associated with a dynamic wave of actin filament during mitosis, and depolymerizing the actin meshwork with either latrunculin A or cytochalasin D 
causes the aggregation of mitochondria and alter the mitochondrial positioning at this cell cycle phase (37). These discrepancies may be due to differential incubations with latrunculin A (10 min (34) or $1 \mathrm{~h} \mathrm{(37)),} \mathrm{or} \mathrm{they} \mathrm{might} \mathrm{be} \mathrm{intrinsic} \mathrm{to} \mathrm{the} \mathrm{resolution} \mathrm{power} \mathrm{of} \mathrm{the} \mathrm{microscopy}$ setups used to image the samples (Airyscan high-resolution microscopy (37) or conventional confocal microscopy (34)).

Overall, mitochondrial segregation at mitosis is a complex, but well-coordinated process in mammalian cells: after the release of mitochondria from motor proteins during the early stages of mitosis, actin cables ensure the uniform distribution of mitochondria prior to cell division.

The requirements for mitochondrial transport in proliferating cells and in cells largely in quiescence share functional similarities, although in specific cell types as neurons the mechanisms of mitochondrial transport on cytoskeletal tracks have been better characterized. Neurons mostly rely on mitochondrial ATP for their survival, and they maintain a comparatively higher number of mitochondria than other cell types. Neurons typically have higher ATP demands at synapses, and this finding is supported by the high amount of mitochondria that can be found at these locations following their transport from the cell body. Similarly, the dependence of mitochondria on the nuclear genome for organelle-specific turnover programs necessitates the transport of damaged mitochondria back from the axon and dendrites to the cell body (38).

As in other cell types, mitochondria in neurons travel long-distance along the microtubule cytoskeleton, and short-distance along the actin network (39). The long-distance transport of mitochondria along microtubules is facilitated by kinesins and dynein (40). There are three classes of kinesin motors: the major transporter class Kinesin-1 family (KIF5s - KIF5A, KIF5B and KIF5C-), the Kinesin-3 family (KIF1B- $\alpha$ ) and Kinesin-Like Protein 6 (KLP6) (41, 42). As introduced above, the loading of kinesins on mitochondria is performed with the help of the adaptor protein Milton in Drosophila, or the TRAK proteins in mammals. Milton links the OMM protein dMiro in Drosophila/MIRO1 and MIRO2 in mammals (43) to the cargo binding domain of KIF5. This complex constituted by MIRO (receptor), KIF5 (motor), and Milton/TRAKs (adaptors) facilitates the anterograde mitochondrial movement of mitochondria $(36,42)$. Although the complete mechanism of mitochondrial transport by KIF1B- $\alpha$ and KLP6 motor proteins is not well understood yet, their loading on mitochondria appears to be facilitated by the adaptor protein KBP (kinesin binding protein) $(44,45)$. Impairing the function of KLP6 by RNAi in C. elegans was shown to cause an alteration of mitochondrial morphology (46). Similarly, HeLa and Neuro-2a cells expressing a mutant KLP6 construct lacking the motor domain showed altered mitochondrial morphology and an inhibited transport of mitochondria in neurites of differentiated Neuro-2a cells (46) (Fig. 3A).

The retrograde mitochondrial motion in neurons is driven by the dynein motor complex and its partner dynactin (47). The dynein motor is a multimeric protein consisting of two heavy chains (DHC), several intermediate chains (DICs) and dynein light intermediate chains (DLICs), and dynein light chains (DLC) (47-49). The dynein heavy chains act as the motor, and the other subunits participate to the association of the dynein motor with the cargo and in regulating the mobility of dynein along the microtubule tracks. However, the large structure of dynein complexifies experimental analyses, and the dynein-mediated mitochondrial transport mechanism has not been fully elucidated yet. One study suggests that the DLC protein 
TCTEX1 favors the binding of dynein with the OMM protein voltage-dependent anionselective channel (VDAC) (50). Then, dynactin binds directly to dynein, and it also binds to microtubules through its $\mathrm{p} 150^{\text {Glued }}$ component (51). Dynein in complex with dynactin is then capable to interact with Milton/TRAK2 and MIRO to mediate retrograde mitochondrial transport $(36,52)$ (Fig. 3A and B).

Although most mitochondrial transport takes place on microtubule tracks with the help of kinesins and dynein, the short distance movements in dendritic spines are orchestrated by myosins on the actin network (53). As introduced above, myosins are ATP-dependent motor proteins and out of 18 classes of myosin proteins, Myo-19 $(53,54)$ and Myo-5 were associated with mitochondrial transport in mammalian cells, with Myo-5 acting through the SPIRE1 actinnucleating protein $(55,56)$. Both Myo-19 and Myo-5 were shown to bind to MIRO proteins to facilitate the mitochondrial transport (36) (Fig. 3C). However, the involvement of these motors in specific cells as neurons remains to be fully elucidated.

Mitochondrial transport is crucial for the survival of neurons and for the maintenance of synapses. Perturbations of mitochondrial transport have been linked to neurodegenerative diseases such as Alzheimer's (57-61) and Parkinson's (62-66), amyotrophic lateral sclerosis (67-70), schizophrenia $(71,72)$ and Huntington's diseases $(73-75)$.

\section{Asymmetric mitochondrial inheritance during mitosis and its link to stemness}

In general, somatic cell division show a symmetric distribution of mitochondria into the two daughter cells, which receive comparable amounts of mitochondria with similar membrane potential levels. DNM1L-mediated mitochondrial fission is critical for the correct distribution of mitochondria in the daughter cells. AURKA and the Cyclin B/CDK1 complex, together with RALA (small Ras-like GTPase) and its adaptor and RALBP1 were shown to be key for mitochondrial fission at mitosis. AURKA phosphorylates RALA at Ser194 and upon phosphorylation, RALA localizes to mitochondria and favors the localization of its effector RALBP1 and of DNM1L itself to this compartment (32). Impairing this cascade of events alters DNM1L-dependent mitochondrial fission, resulting in the asymmetric segregation of mitochondria in the two daughter cells (32).

Unlike in somatic cells, the uneven distribution of "aged" mitochondria often occurs during the asymmetric cell division of stem cells. One of the daughter cells receives the majority of newlysynthesized mitochondria and maintains the stem cell fate, while the daughter cell receiving a higher proportion of "aged" mitochondria will acquire a differentiated, non-stem fate (76). In addition, the inhibition of DNM1L-mediated mitochondrial fission events in the stem cell blocks the asymmetrical distribution of "old" mitochondria, leading to the loss of stem cell properties (76). Therefore, mitochondrial fission is also crucial for the maintenance of the stem cell phenotype. A similar study showed that the alteration of mitochondrial dynamics, or the presence of mitochondrial stress during the division of hematopoietic stem cells (HSCs) causes the asymmetric distribution of mitochondria in the daughter cells (77). The cells receiving dysfunctional mitochondria fail to manage the biosynthetic demands needed to progress throughout the cell cycle, and undergo replicative senescence (77). Another study illustrated that LPS-activated lymphocytes divide asymmetrically, and give rise to daughter cells having 
different sets of "aged" mitochondria (78). Based on the relative content of aged mitochondria, lymphocytes will enter separate metabolic pathways. The cells that follow PI3K-dependent catabolic pathways were shown to contain "younger" mitochondria, to clear damaged organelles more efficiently and self-renew as naive stem cells. On the contrary, cells following AMPK-related anabolic pathways contain more "aged" mitochondria and undergo senescence (78). Although the respective molecular mechanisms and the player involved still remain to be fully understood, these studies show that the asymmetric partitioning of mitochondria is key to cell metabolism, together with the capacity of the cell to maintain stemness in specific cell types.

The transport of mitochondria among cell populations as a potential route to adapt cell metabolism and contribute to chemoresistance in cancer

Metabolic adaptation is an essential aspect for survival in the adverse tumor microenvironment, where every cell is undergoing multiple rounds of uncontrolled cell division. In such a competitive environment for nutrients availability, it is challenging to fulfill both substrate and energy requirements. Mitochondria play an essential role by fueling the energy requirements of the cancer cell by using various substrates, maintaining a pool of cancer stem cells, and helping in the development of metastasis (79-81). However, it is not clear whether the role(s) of mitochondria in these processes is played by the entire mitochondrial network within a particular cell population, or it is due to an exchange of mitochondria among the various cell populations constituting a tumor. It has been shown that mitochondria can be transferred from adult stem cells and/or somatic cells to defective cells with no mitochondrial DNA ( $\rho 0$ cells) $(82,83)$. This transfer restores aerobic respiration in $\rho 0$ cells, and provided the first evidence of mitochondrial transfer between two cell populations (82). After this report, mitochondrial transfer was shown to occur under various paradigms: from the pluripotent mesenchymal stem cells to lung epithelial cells to protect from cigarette smoke-induced damage (84); from mesenchymal stem cells to epithelial cells to protect the injured cells in ischemia-reperfusion models $(85,86)$; from mesenchymal stem cells to rotenone-stressed mitochondrial myopathy, encephalomyopathy, lactic acidosis, and stroke-like episodes (MELAS) fibroblasts to rescue their bioenergetics capabilities (87). Furthermore, the transfer of dysfunctional mitochondria from neurons to astrocytes and the consequent clearing of defective mitochondria within the astrocytes (88) was shown to provide neuroprotection in an animal model of stroke. In the context of cancer, the transfer of mitochondria was shown to occur from endothelial cells to cancer cells (89), and from bone marrow stromal cells to leukemic cells (90). This transfer protects the cancer cells from apoptosis and increases its chemoresistance. Last, the intracellular transfer of functional mitochondria from a highly invasive bladder cancer cells increases their metastatic and invasive properties, and results in an increased tumor size in a T24 xenograft mice model (91).

The transport of mitochondria to active sites of inflammation or metastasis was also shown to be key to disease progression. Lymphocyte migration is vital for adequate immunological response at the site of injury or inflammation, and it is guided by the cytokines or chemokines released at the site of the injury $(92,93)$. Lymphocyte migration is an energy-consuming 
process that requires high quantities of ATP for lymphocytes to adhere, contract and perform protrusions. In this light, mitochondria play a crucial role in lymphocyte migration (94): mitochondrial fission and redistribution were shown to be critical for migration, while an increase in mitochondrial fusion slows down this process (94).

Similarly, cell migration is a characteristic feature of cancer cells that allows them to metastasize away from the primary site of the tumor (95). Cytoskeletal proteins are known to be crucial for cell migration and cancer metastasis, and many dugs developed to target cytoskeletal stability and functions are under investigation and show promising results (9698). However, the involvement of mitochondrial transport and its role in providing ATP for cell migration has been neglected. A study on epithelial breast cancer cell lines shows that the localization of mitochondria to the leading edge of the migrating cell increases the migration velocity and helps directional persistence (99). Similarly to the impact of mitochondrial fission for lymphocyte migration (94), promoting mitochondrial fusion by overexpressing OPA1, blocking fission by overexpressing a dominant-negative form of DNM1L (DNM1L ${ }^{\mathrm{K} 38 \mathrm{~A}}$ ) or impairing mitochondrial transport using a MIRO1 shRNA slow down the migration of cancer cells (99). These data further corroborate the importance of mitochondrial dynamics and transport in cancer metastasis, although our current view of the importance of their interplay for cancer progression is still partial.

\section{Mitochondrial quality control as a requirement for cell differentiation, fate acquisition and stemness.}

As introduced above, the capacity of cells to activate and achieve the clearance of dysfunctional mitochondria is key to cell physiology, and organelle turnover heavily relies on mitochondrial dynamics and transport (100). Mitochondria are selectively cleared by mitophagy, an organelle-specific autophagy pathway $(101,102)$. In mitophagy, dysfunctional mitochondria are engulfed in a double-membrane vesicles known as autophagosomes and then degraded by lysosomes. Mitochondrial quality control begins before the entry into the cell cycle, as cells with defective mitochondria were shown to remain in $\mathrm{G}_{0}$ (103). Interestingly, an in vivo study in Drosophila showed that the disruption of mitochondrial complex I functions can compromise mitochondrial membrane potential, ATP synthesis, and it causes $\mathrm{G}_{1}-\mathrm{S}$ arrest (104). A recent report linked the PINK1/PARKIN mitophagy pathway and a successful cell cycle progression. Upon widespread mitochondrial dysfunction, induced by incubating cells with an oligomycin/antimycin cocktail, the PINK1/PARKIN pathway was shown to sequester the mitotic Tank Binding Kinase 1 (TBK1) to damaged mitochondria. Genetic ablation or pharmacological inhibition of TBK1 triggered cell cycle arrest at mitosis (105). These studies suggest that mitochondrial quality control is a prerequisite for cell cycle entry and progression. Whether these events are important also in physiological paradigms of mitophagy, and whether the mitochondrial transport machinery is involved in basal quality control events is currently a matter of intense investigation in the field. 
In the sections below, we will review our current knowledge on the main mechanisms of basal mitophagy, and explore the consequences of impaired mitophagy for cell proliferation, stemness and fate acquisition.

\section{Mechanisms of mitophagy in red blood cells}

The maturation of erythroblasts into mature red blood cells is a process commonly known as terminal erythropoiesis. It starts in the bone marrow within erythroblastic islands, which consist of a central macrophage surrounded by erythroblasts, and it ends in the bloodstream, where reticulocytes complete their maturation in approximately two days $(106,107)$. The maturation of erythroblasts into red blood cells leads to profound changes in cell morphology, such as the loss of nearly $20 \%$ of the plasma membrane surface area, an overall reduced cell volume, the increased association of the cytoskeleton with the outer plasma membrane, enucleation and the loss of all residual cytoplasmic organelles, such as the Golgi apparatus, the endoplasmic reticulum (ER), mitochondria and ribosomes (106).

The disappearance of mitochondria during terminal erythropoiesis gathered significant attention after the discovery that the main mechanism of mitochondrial clearance in erythroblast maturation is mitophagy (107). During the final step of erythroid differentiation LC3, an ubiquitin-like modifier required for the growth of autophagosomal membranes is converted from its unmodified form - known as LC3-I - to a lipidated form, LC3-II (108). The presence of autophagy during erythroid differentiation was confirmed by the work of Mortensen et al, where it was shown that the conditional knockout of the essential autophagy gene $A T G 7$ in mouse erythrocytes induces the accumulation of damaged mitochondria with altered membrane potential $(\Delta \Psi \mathrm{m})$, increased susceptibility to cell death and anemia (109).

During erythroblast maturation, it was shown that the outer mitochondrial membrane protein NIP3-like protein X (NIX), also named Bcl-2/adenovirus E1B $19 \mathrm{kDa}$ interacting protein 3like (BNIP3L) induces a loss of $\triangle \Psi \mathrm{m}$ and the recruitment of LC3 to mitochondria (110). These events target mitochondria to autophagosomes for clearance during erythroid maturation. At the molecular level, NIX plays the role of a mitophagy receptor by recruiting LC3 and its cognate protein GABARAP, to damaged mitochondria through its amino-terminal LC3interacting region (LIR) (111). Mice lacking the NIX:LC3/GABARAP interaction showed an altered mitochondrial clearance in maturing reticulocytes, a restored $\Delta \Psi \mathrm{m}$, altered erythroid maturation, and anemia.

Other proteins were also shown to play a role in erythroid maturation, such as the serinethreonine kinase ULK1 (Uncoordinated 51-Like Autophagy Activating Kinase 1). ULK1 deficiency was shown to delay the clearance of mitochondria in mouse reticulocytes and embryonic fibroblasts (112). The mitophagy-inducing function of ULK1 during erythroid maturation was shown to require AMPK activity, and more specifically the activity of the a1 isoform (PRKAA1) (113). The lack of PRKAA1 activity (by PRKAA1 inactivation or gene deletion in mice erythroid precursors) decreases ULK1 phosphorylation on Ser555, a key modification required for the nucleation of autophagic vesicles. The absence of this phosphorylation prevents the direct association of ULK1 with autophagy-related partners such 
as RB1CC1, the formation of BECN1-PtdIns3K complexes, and it ultimately inhibits mitophagy. Mitochondria not undergoing mitophagy display excessive mitochondrial ROS levels and overall oxidative stress, which was proposed to cause the destruction of erythrocytes by hemolysis. Although ATG7 and ULK1 were shown to play key roles in mitophagy during terminal erythropoiesis, their absence does not completely abolish mitochondrial turnover, and it suggests the existence of an alternative pathway that can be implicated in this process $(112$, $114,115)$. In this optic, RAB9A, a member of the Rab GTPase family implicated in endosome trafficking (116), was shown to trigger mitophagy activation in erythroid leukemic cell lines and in vivo even when the canonical, ATG7-dependent autophagy pathway is blocked (115, 117) (Fig. 4). However, further studies are required to understand the spatiotemporal activation of these two pathways in physiological conditions.

Mitochondrial elimination by mitophagy during the maturation of red blood cells is an important process, and its deficiency is associated with many diseases such as myelodysplastic syndromes anemia and sickle cell disease $(118,119)$. This is why investigating the mechanisms and actors implicated in the clearance of mitochondria from red blood cells is necessary to unravel how this process is compromised in patients, and may help developing new therapeutic strategies.

\section{Mitophagy in Stem Cell Maintenance and Differentiation}

As described above, the correct maintenance of the blood system is critical to homeostasis. In addition to the mitophagy mechanisms regulating terminal erythropoiesis, HSCs continuously repress oxidative metabolism and eliminate active mitochondria via mitophagy to remain in a quiescent state (120). HSCs were shown to rely on anaerobic glycolysis for their energy needs, and this is a potential strategy used by the stem cell to prevent the accumulation of high levels of ROS that can lead to blood aging phenotypes $(121,122)$. It has been demonstrated that mitophagy in HSCs involves the autophagy factor ATG12 (120). The knockout of ATG12 in mice HSCs induces an increase in the total number of mitochondria, which were shown to adopt an elongated morphology. Under these conditions, HSCs also display an increased mitochondrial membrane potential compared to the controls, revealing an accumulation of active mitochondria which cannot undergo ATG12-mediated autophagic degradation. In a parallel study, Ito et al. have demonstrated that Tie2+ HSCs, a subpopulation of mouse HSCs, can maintain their stemness potential by upregulating a PINK1/PARKIN-dependent mitophagy program (123). Complementary data show that the absence of PINK1 in mouse embryonic fibroblasts (MEFs) lowers their capacity to be reprogrammed into induced pluripotent stem cells (iPSCs) and conversely, PINK1-deficient iPSCs tend to spontaneously differentiate and to lose their ability to maintain stemness proprieties (124). In addition, the overall reprogramming of MEFs into iPSCs was recently associated with a decrease in mitochondrial mass and an increase of BNIP3L/NIX-dependent mitophagy, and this independently of a $\Delta \Psi \mathrm{m}$ loss (125).

Mitophagy has also been shown to be implicated in the differentiation of mouse neuroblast stem cells into retinal ganglion cells (RGCs). This process has been found to involve NIX- 
dependent mitophagy induced by hypoxia to eliminate mitochondria and shift their metabolism from mitochondrial respiration towards glycolysis (126). In muscle differentiation, mitophagy was also found to play a role in differentiating primitive myoblasts into mature myotubes (127). This was shown to require mitochondrial network remodeling and the induction of SQSTM1 (sequestosome1)-mediated mitophagy. Mitophagy in this model temporally occurs before the biogenesis of new mitochondria, and this transition parallels a metabolic shift: myoblasts were found to be mainly in a glycolytic state, while mature myotubes switch to oxidative phosphorylation.

\section{Basal mitophagy in Drosophila, C. elegans and mice: paternal mitophagy after fertilization}

Despite the fact that spermatozoan mitochondria are found in the oocyte upon fertilization, only maternal mitochondria are inherited in the majority of eukaryotic species (128). Several reports have shown that paternal mitochondria sperm-derived (PMS) are eliminated shortly after fertilization. In mice, PMS disappear from embryos during the 4-cell to 8-cell stage transition (129). In 2011, Sato and Sato demonstrated that the elimination of PMS in C. elegans requires autophagy, as PMS were maintained in zygotes with defective autophagy, and they were detectable even at the first larval stage (130). By following the expression of LGG-1 and LGG2, the C. elegans homologs of LC3, Rawi et al. showed that the entry of the spermatozoan organelles into the oocyte upon fertilization triggers an autophagy response (131). Under these conditions, structures positive for LGG-1 and LGG-2 were found to surround PMS. Similarly, several autophagosomal markers such as LC3, GABARAP, SQSTM1 and Lys63-positive ubiquitin chains were found in the vicinity of ubiquitinated PMS in the fertilized mouse oocyte and corroborating the role of autophagy for the clearance of paternal mitochondria (131). However, the molecular mechanisms of mitochondrial turnover seem to partially differ among species, as mammalian PMS are ubiquitinated while C. elegans sperm mitochondria are not $(131,132)$.

The elimination of paternal mitochondria has been also shown to occur in Drosophila. Transgenic flies with fluorescently-tagged sperm mitochondria revealed that PMS disappear 90 minutes after egg laying (133). Eggs fertilized by DJ-GFP, a fluorescent sperm-specific mitochondrial protein, and maternally expressing the fluorescent autophagy reporter mCherryAtg8, the Drosophila homolog of LC3, showed a localization of Atg8-positive vesicles in the vicinity of DJ-positive paternal mitochondria, which start to be degraded 30 minutes after egg laying. In contrast to C. elegans, ubiquitination seems to be required for paternal mitochondrial clearance in Drosophila. Directly after fertilization, PMS are ubiquitinated and SQSTM1, an autophagy receptor recognizing ubiquitylated proteins (134), is recruited to the PMS. While PARKIN does not appear to be involved in the paternal clearance of mitochondria in Drosophila, it seems to be required for the mammalian turnover of PMS $(133,135)$.

Recently, Prohibitin 2 (PHB2) an inner mitochondrial membrane protein has been found to function as a key mitophagy receptor for PARKIN-mediated mitophagy in mammalian cells and to play a critical role in the elimination of paternal mitochondria in C. elegans (136). By following the fate of paternal mitochondria stained by MitoTracker Red in fertilized C. elegans 
oocytes, it has been shown, that the knockdown of PHB2 in spermatozoids impaired paternal mitochondrial clearance. In this study, it was shown that PHB2 has an LC3-interacting motif allowing it to bind to LC3 during mitophagy. However, PHB2 is an inner mitochondrial membrane protein and its interaction with LC3 requires its exposure to the cytosol. Indeed, it was demonstrated that a proteasome-dependent OMM rupture is necessary for the interaction between PHB2 and active, lipidated LC3 (LC3-II) (136). These findings were further corroborated in vivo, as paternal mitochondria were shown to undergo depolarization and a ruptured OMM upon the entry of the PMS into the oocyte in C. elegans (137).

\section{Conclusions and open questions.}

Our knowledge on how mitochondrial dynamics, transport and mitophagy are orchestrated in specific cell types and in physiological conditions is core to our understanding of how cell homeostasis is maintained. These functions are not only required to maintain proper mitochondrial functionality, but they also allow the correct partitioning of the mitochondrial pool to daughter cells during cell division. In addition, the molecular machineries involved in maintaining these mitochondrial functions were shown to directly participate to the acquisition of cell fate and stemness, and to regulate the overall metabolic capacity of the cell. Failure in regulating these functions by altering the abundance of the molecular players involved has been linked to pathological conditions, such as neurodegenerative disorders or cancer.

Although the importance of mitochondrial dynamics, transport or clearance is increasingly clear, our knowledge of how these functions are mutually connected at the physiological level remains partial. Recent data shed light on paradigms and molecular actors of basal, piecemeal mitophagy in mammalian cells, which appears to be turned on when cells rely on oxidative phosphorylation for ATP production $(138,139)$. So far, the major players appear to be ATG8 proteins, SQSTM1 and the import protein SAMM50, while no involvement of PINK1 or of DNM1L has been found $(138,139)$. Therefore, piecemeal mitophagy seems to be different from the physiological clearance of paternal mitochondria, which utilizes the PINK1/PARKIN pathway and mitochondrial dynamics actors instead (135). However, differences in the abundance of proteins regulating mitochondrial dynamics can be observed in SAMM50induced piecemeal mitophagy (139). Whether this is directly linked to a mitochondrial transport impairment or a chronic protein import deficiency still remains to be ruled out. Together, it appears that several paradigms of physiological mitophagy exist, each of them being activated in specific cell types or metabolic conditions, and each of them showing a unique set of molecular actors only partially shared with the other ones. Whether these paradigms all rely on an efficient transport machinery still remains to be determined.

In conclusion, the link between physiological paradigms of mitophagy and their relationship to organelle transport still remains to be fully elucidated, together with the importance that these processes have for mitochondrial segregation at cell division in both symmetrically- and asymmetrically-dividing cells. Last, future studies are needed to explore how the adaptation of cellular and mitochondrial metabolism can shape mitochondrial transport and basal mitophagy pathways, and the consequences that this metabolic adaptation has for cell proliferation or 
quiescence, differentiation or stemness, and fate acquisition in physiological and pathological conditions. 
Figures and figure legends

Phases of cell cycle

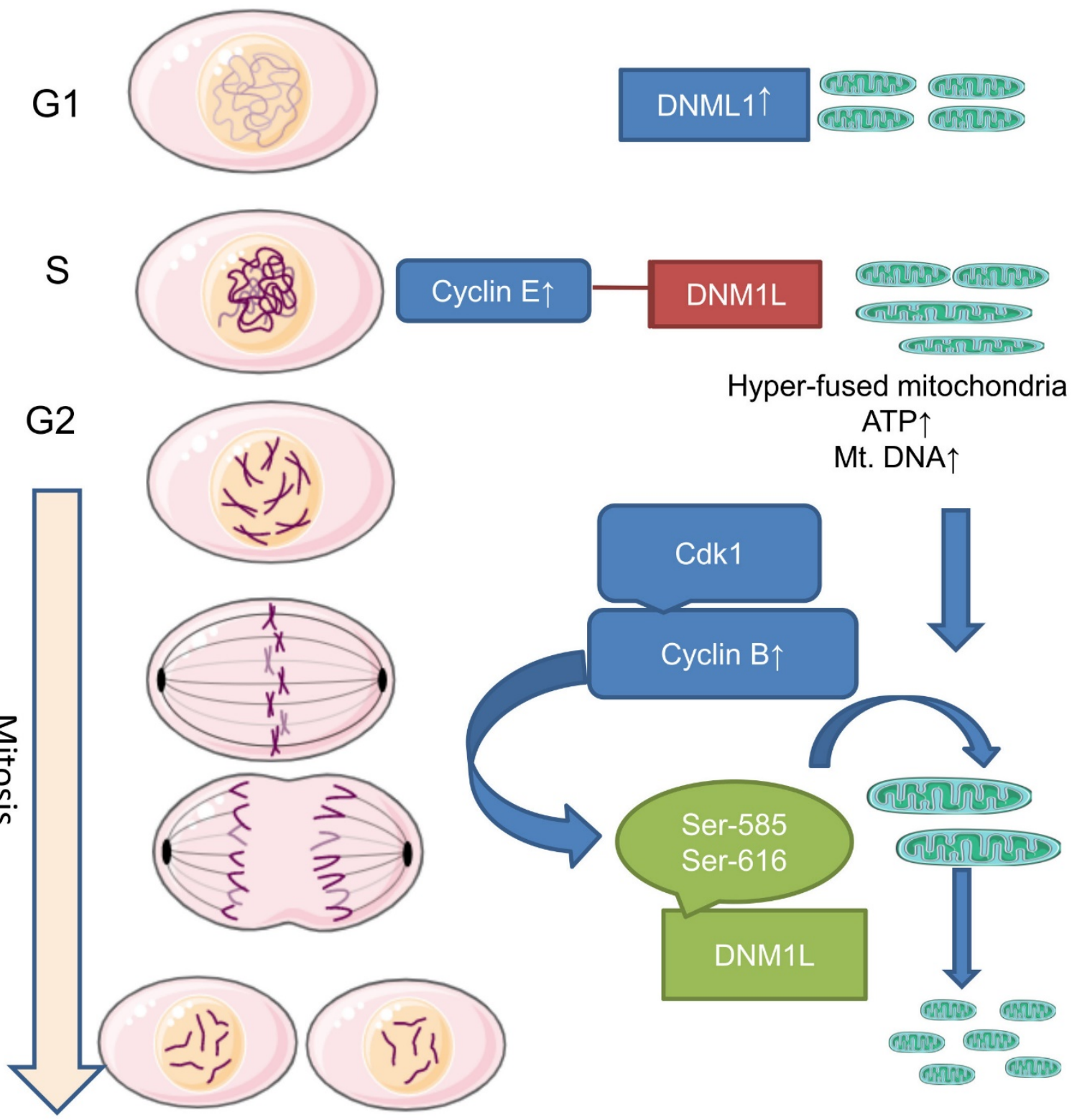

Fig. 1. Changes in mitochondrial dynamics during cell cycle. The levels of Cyclin E increase during $\mathrm{S}$ phase, and this inhibits DNM1L-mediated mitochondrial fission in favor of fusion. The resulting hyper-fused mitochondria have high ATP synthesis capabilities, that sustain cycle progression. At mitosis, Cyclin B/CDK1 activate DNM1L by phosphorylating it on Ser585 and Ser616 residue. These modifications cause mitochondrial fission, which is mandatory for cells to progress throughout mitosis. Figure assembled using templates freely available on $\underline{\mathrm{https}}$ ://bioicons.com/ and on https://smart.servier.com/) 


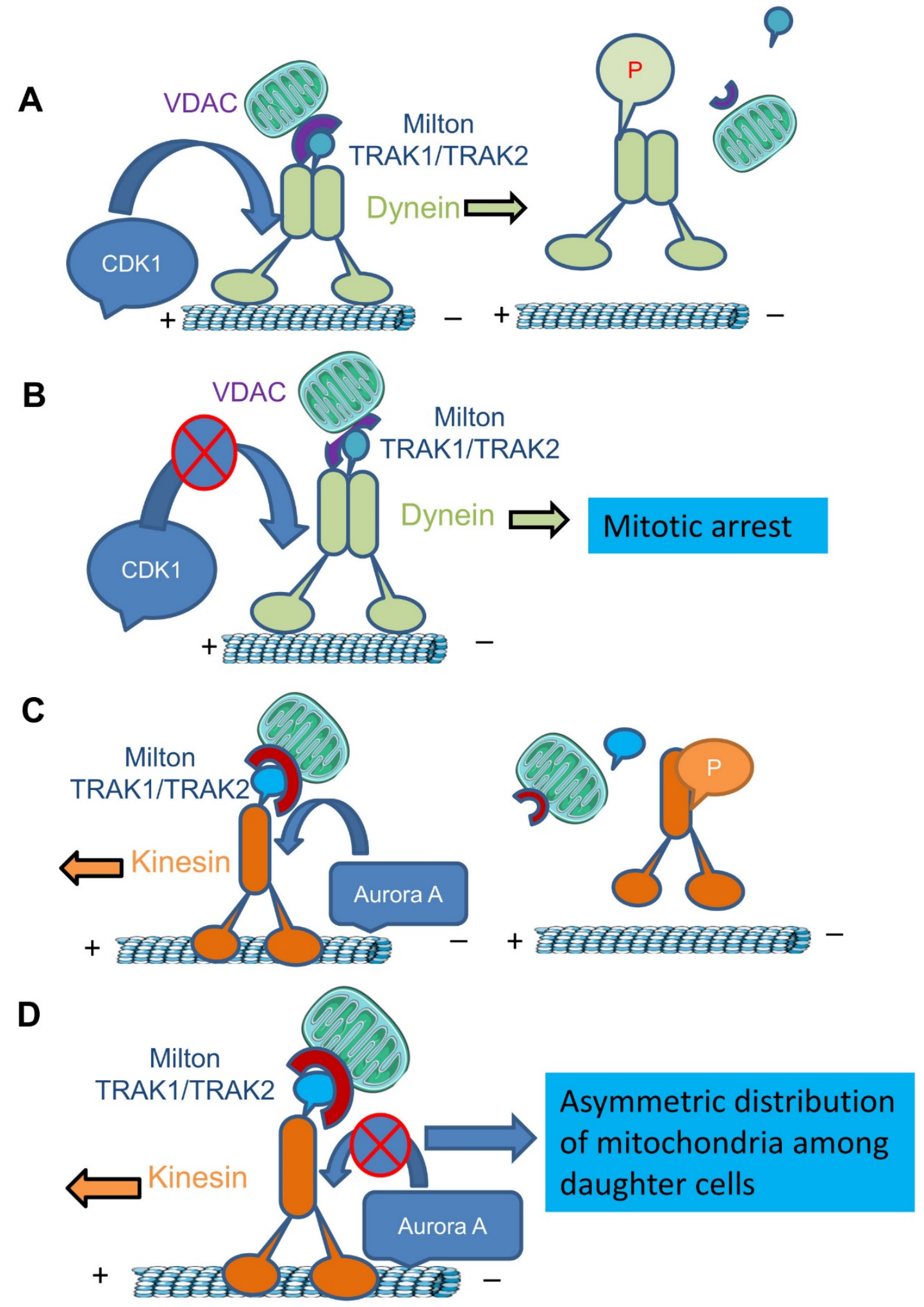

Fig. 2. The release of motor proteins from mitochondria during mitosis is essential for successful cell cycle progression (A) CDK1 causes the phosphorylation of dynein, which causes release of mitochondria from this motor. (B) Inhibiting the release of mitochondria from dynein, or the forced attachment of dynein to mitochondria causes cell cycle arrest at mitosis. (C) Aurora A/AURKA causes phosphorylation of kinesins, which causes the release of mitochondria from the motor protein. (D) Inhibiting the release of mitochondria from kinesins, or the forced attachment of kinesins to mitochondria causes the asymmetric distribution of 
mitochondria at mitosis. Figure assembled using templates freely available on https://bioicons.com/ and on https://smart.servier.com/) 
A Anterograde

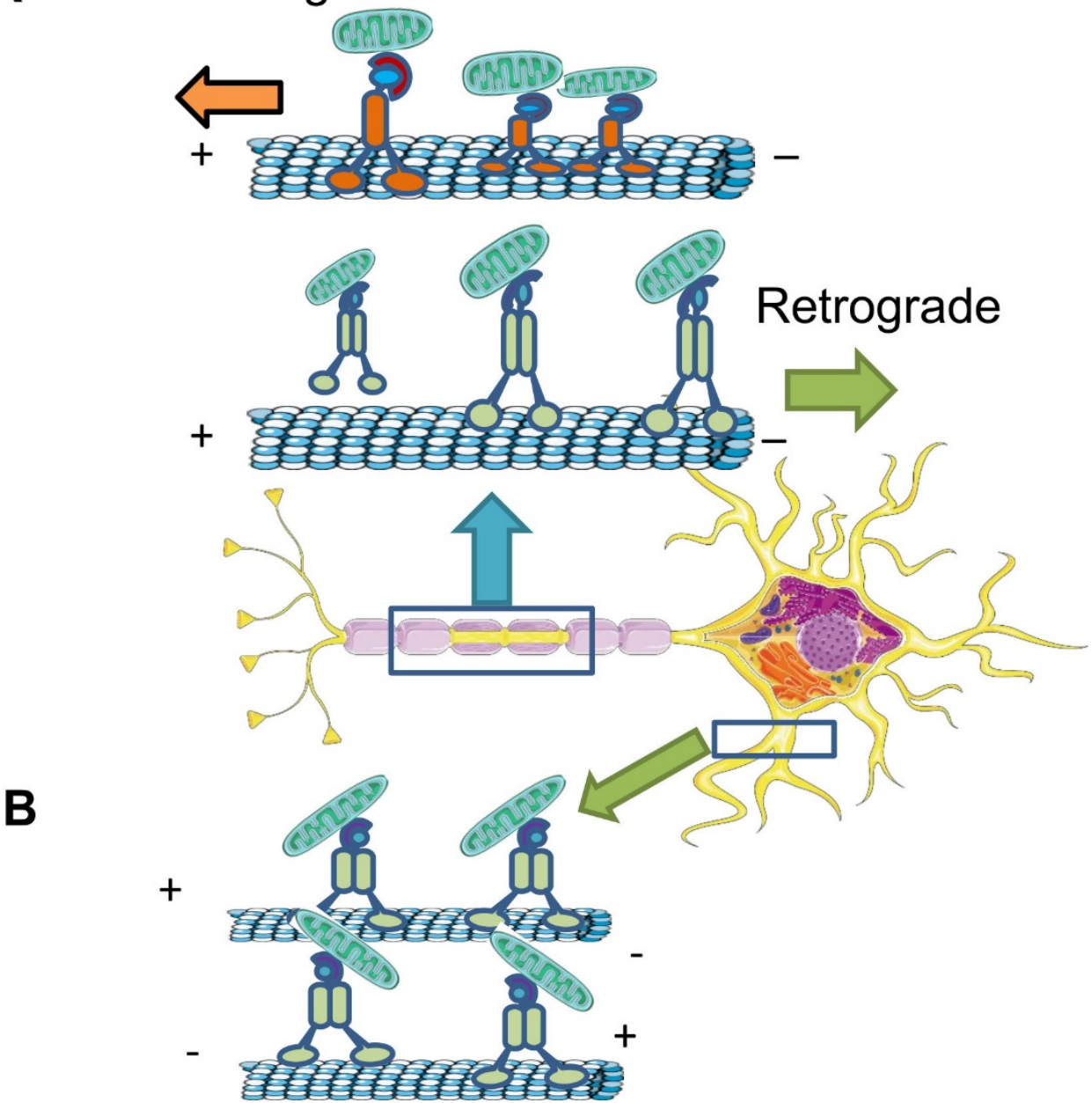

C

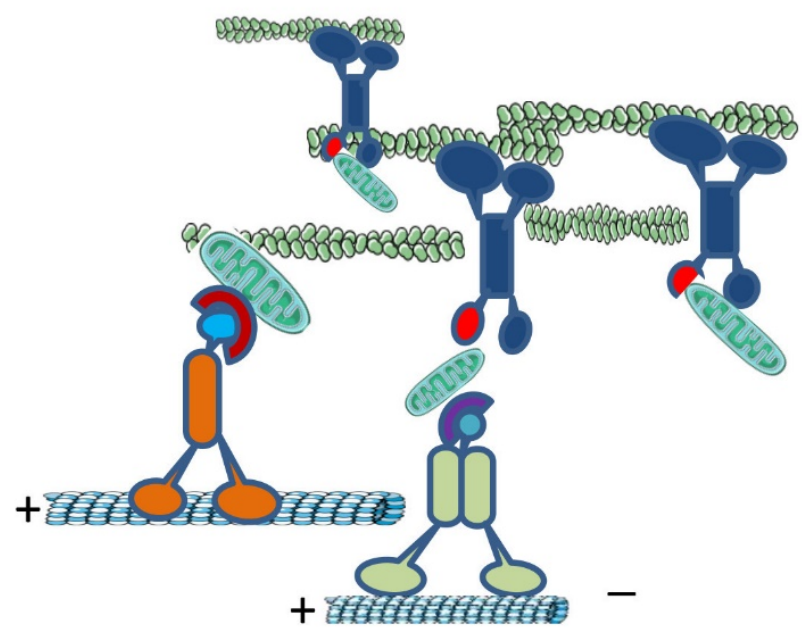

Fig. 3. Mitochondrial transport in neurons. (A) Mitochondrial transport is carried by dynein and kinesins. Due to the difference in polarity of microtubules in axon, mitochondrial anterograde movement is carried by kinesins, and retrograde movement by dynein. (B) Microtubule in dendrite have mixed polarity and unlike in axons, both anterograde and retrograde movements are facilitated by dynein. (C) Short-distance mitochondrial transport in the actin-rich dendritic spines is performed by myosins. Mitochondria previously traveling on 
microtubule tracks can be transferred to myosin motors, which facilitate their anchoring on actin tracks. Figure assembled using templates freely available on https://bioicons.com/ and on https://smart.servier.com/) 


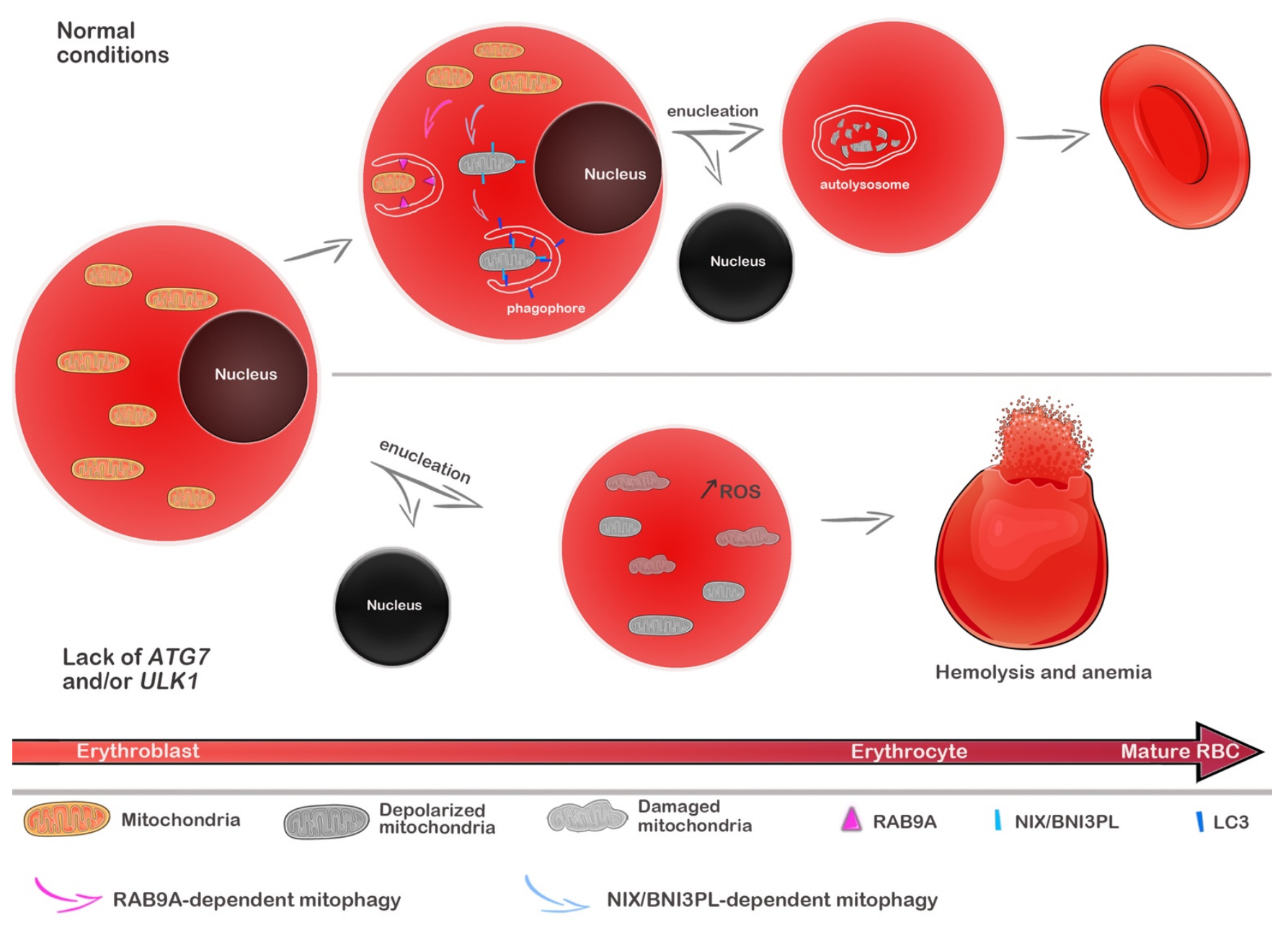

Fig. 4. Mitochondrial elimination by mitophagy during the maturation of red blood cells. When red blood cell maturation is not perturbed, mitochondrial elimination by mitophagy occurs following two pathways: a NIX/BNI3PL-dependent mitophagy, and a RAB9Adependent clearance. NIX/BNI3PL induces mitochondrial depolarization and recruitment of LC3 on autophagosomal membranes, followed by degradation of the cargo. RAB9A-dependent mitophagy was also shown to occur in parallel. In case of $A T G 7$ deficiency, altered and depolarized mitochondria accumulate in erythrocytes, while ULK1 deficiency results in delayed mitochondrial clearance. Mitochondria not undergoing mitophagy display excessive mitochondrial ROS levels and overall oxidative stress, which was proposed to be the leading cause for the destruction of erythrocytes by hemolysis and anemia. Figure assembled using templates freely available on https://bioicons.com/ and on https://smart.servier.com/) 


\section{Author Contributions}

R.K.S. and A.C. wrote the manuscript; G.B. conceptualized, wrote and reviewed the manuscript and provided funding.

\section{Funding}

This work was supported by the Centre National de la Recherche Scientifique (CNRS), the Ligue Contre le Cancer Comités d'Ille et Vilaine, et du Finistère, and the Association pour la Recherche Contre le Cancer (ARC) to G.B. R.K.S. was supported by a fellowship from the Brittany region, France (Région Bretagne).

\section{Conflicts of Interest}

The authors declare no conflict of interest.

\section{References}

1. Osellame LD, Blacker TS, Duchen MR. Cellular and molecular mechanisms of mitochondrial function. Best Pract Res Clin Endocrinol Metab 26: 711-723, 2012. doi: 10.1016/j.beem.2012.05.003.

2. Lewis MR, Lewis WH. Mitochondria (and other cytoplasmic structures) in tissue cultures. Am J Anat 17: 339-401, 1915. doi: https://doi.org/10.1002/aja.1000170304.

3. Tilokani L, Nagashima S, Paupe V, Prudent J. Mitochondrial dynamics: overview of molecular mechanisms. Essays Biochem 62: 341-360, 2018. doi: 10.1042/EBC20170104.

4. Murata D, Arai K, Iijima M, Sesaki H. Mitochondrial division, fusion and degradation. $J$ Biochem (Tokyo) 167: 233-241, 2020. doi: 10.1093/jb/mvz106.

5. Twig G, Elorza A, Molina AJA, Mohamed H, Wikstrom JD, Walzer G, Stiles L, Haigh SE, Katz S, Las G, Alroy J, Wu M, Py BF, Yuan J, Deeney JT, Corkey BE, Shirihai OS. Fission and selective fusion govern mitochondrial segregation and elimination by autophagy. EMBO J 27: 433-446, 2008. doi: 10.1038/sj.emboj.7601963.

6. Kraus F, Ryan MT. The constriction and scission machineries involved in mitochondrial fission. J Cell Sci 130: 2953-2960, 2017. doi: 10.1242/jcs.199562.

7. Ni HM, Williams JA, Ding WX. Mitochondrial dynamics and mitochondrial quality control. Redox Biol 4: 6-13, 2015. doi: 10.1016/j.redox.2014.11.006.

8. Youle RJ, Bliek AM van der. Mitochondrial Fission, Fusion, and Stress. Science 337: 10621065, 2012. doi: 10.1126/science. 1219855 .

9. Westermann B. Mitochondrial fusion and fission in cell life and death. Nat Rev Mol Cell Biol 11: 872-884, 2010.

10. Twig G, Shirihai OS. The interplay between mitochondrial dynamics and mitophagy. Antioxid Redox Signal 14: 1939-1951, 2011. doi: 10.1089/ars.2010.3779.

11. Suen D-F, Norris KL, Youle RJ. Mitochondrial dynamics and apoptosis. Genes Dev 22: 1577-1590, 2008. doi: 10.1101/gad.1658508.

12. Moore AS, Holzbaur EL. Mitochondrial-cytoskeletal interactions: dynamic associations that facilitate network function and remodeling. Curr Opin Physiol 3: 94-100, 2018. doi: 
10.1016/j.cophys.2018.03.003.

13. Fransson $\backslash$ AAsa, Ruusala A, Aspenström P. The atypical Rho GTPases Miro-1 and Miro-2 have essential roles in mitochondrial trafficking. Biochem Biophys Res Commun 344: 500-510, 2006. doi: 10.1016/j.bbrc.2006.03.163.

14. Misko A, Jiang S, Wegorzewska I, Milbrandt J, Baloh RH. Mitofusin 2 Is Necessary for Transport of Axonal Mitochondria and Interacts with the Miro/Milton Complex. J Neurosci 30: 42324240, 2010. doi: 10.1523/JNEUROSCI.6248-09.2010.

15. Varadi A, Johnson-Cadwell LI, Cirulli V, Yoon Y, Allan VJ, Rutter GA. Cytoplasmic dynein regulates the subcellular distribution of mitochondria by controlling the recruitment of the fission factor dynamin-related protein-1. J Cell Sci 117: 4389-4400, 2004. doi: 10.1242/jcs.01299.

16. Nunnari J, Walter P. Regulation of Organelle Biogenesis. Cell 84: 389-394, 1996. doi: 10.1016/S0092-8674(00)81283-0.

17. Simon VR, Karmon SL, Pon LA. Mitochondrial inheritance: Cell cycle and actin cable dependence of polarized mitochondrial movements in saccharomyces cerevisiae. Cell Motil Cytoskeleton 37: 199-210, 1997. doi: 10.1002/(SICI)1097-0169(1997)37:3<199::AID$\mathrm{CM} 2>3.0 . \mathrm{CO} ; 2-2$.

18. Higuchi R, Vevea JD, Swayne TC, Chojnowski R, Hill V, Boldogh IR, Pon LA. Actin dynamics affect mitochondrial quality control and aging in budding yeast. Curr Biol 23: 2417-2422, 2013. doi: 10.1016/j.cub.2013.10.022.

19. Lazzarino DA, Boldogh I, Smith MG, Rosand J, Pon LA. Yeast Mitochondria Contain ATP-sensitive, Reversible Actin-binding Activity. 5: 807-818, 1994.

20. Altmann K, Westermann B. Role of Essential Genes in Mitochondrial Morphogenesis in Saccharomyces cerevisiae $\square$. 16: 5410-5417, 2005. doi: 10.1091/mbc.E05.

21. Boldogh IR, Pon LA. Interactions of mitochondria with the actin cytoskeleton. Biochim Biophys Acta - Mol Cell Res 1763: 450-462, 2006. doi: 10.1016/j.bbamcr.2006.02.014.

22. McFaline-Figueroa JR, Vevea J, Swayne TC, Zhou C, Liu C, Leung G, Boldogh IR, Pon LA. Mitochondrial quality control during inheritance is associated with lifespan and mother-daughter age asymmetry in budding yeast. Aging Cell 10: 885-895, 2011. doi: 10.1111/j.14749726.2011.00731.x.

23. Swayne TC, Zhou C, Boldogh IR, Mcfaline-figueroa R, Charalel JK, Thoms S, Yang C, Leung G, Mcinnes J, Erdmann R, Pon LA. Report Role for cER and Mmrlp in Anchorage of Mitochondria at Sites of Polarized Surface Growth in Budding Yeast. .

24. Altmann K, Frank M, Neumann D, Jakobs S, Westermann B. The class V myosin motor protein, Myo2, plays a major role in mitochondrial motility in Saccharomyces cerevisiae. J Cell Biol 181: 119-130, 2008. doi: 10.1083/jcb.200709099.

25. Van den Bogert C, Muus P, Haanen C, Pennings A, Melis TE, Kroon AM. Mitochondrial biogenesis and mitochondrial activity during the progression of the cell cycle of human leukemic cells. Exp Cell Res 178: 143-153, 1988. doi: 10.1016/0014-4827(88)90385-0.

26. Martínez-Diez M, Santamaría G, Ortega ÁD, Cuezva JM. Biogenesis and dynamic of mitochondria during the cell cycle: Significance of 3'UTRs. PLOS ONE 1: 1-12, 2006. doi: 10.1371/journal.pone.0000107.

27. Mitra K, Wunder C, Roysam B, Lin G, Lippincott-Schwartz J. A hyperfused 
mitochondrial state achieved at G1-S regulates cyclin E buildup and entry into S phase. Proc Natl Acad Sci U S A 106: 11960-11965, 2009. doi: 10.1073/pnas.0904875106.

28. Horbay R, Bilyy R. Mitochondrial dynamics during cell cycling. Apoptosis 21: 1327-1335, 2016. doi: 10.1007/s10495-016-1295-5.

29. Sweet S, Singh G. Changes in mitochondrial mass, membrane potential, and cellular adenosine triphosphate content during the cell cycle of human leukemic (HL- 60) cells. $J$ Cell Physiol 180: 91-96, 1999. doi: 10.1002/(SICI)1097-4652(199907)180:1<91::AID-JCP10>3.0.CO;2-6.

30. Lee S, Kim S, Sun X, Lee JH, Cho H. Cell cycle-dependent mitochondrial biogenesis and dynamics in mammalian cells. Biochem Biophys Res Commun 357: 111-117, 2007. doi: 10.1016/j.bbrc.2007.03.091.

31. Taguchi N, Ishihara N, Jofuku A, Oka T, Mihara K. Mitotic Phosphorylation of Dynaminrelated GTPase Drp1 Participates in Mitochondrial Fission*. J Biol Chem 282: 11521-11529, 2007. doi: 10.1074/jbc.M607279200.

32. Kashatus DF, Lim KH, Brady DC, Pershing NLK, Cox AD, Counter CM. RALA and RALBP1 regulate mitochondrial fission at mitosis. Nat Cell Biol 13: 1108-1117, 2011. doi: $10.1038 /$ ncb2310.

33. Kashatus DF, Lim KH, Brady DC, Pershing NLK, Cox AD, Counter CM. RALA and RALBP1 regulate mitochondrial fission at mitosis. Nat Cell Biol 13: 1108-1117, 2011. doi: $10.1038 / \mathrm{ncb} 2310$.

34. Chung JYM, Steen JA, Schwarz TL. Phosphorylation-Induced Motor Shedding Is Required at Mitosis for Proper Distribution and Passive Inheritance of Mitochondria. Cell Rep 16: 2142-2155, 2016. doi: 10.1016/j.celrep.2016.07.055.

35. Lee S, Kim S, Sun X, Lee JH, Cho H. Cell cycle-dependent mitochondrial biogenesis and dynamics in mammalian cells. Biochem Biophys Res Commun 357: 111-117, 2007. doi: 10.1016/j.bbrc.2007.03.091.

36. López-Doménech G, Covill-Cooke C, Ivankovic D, Halff EF, Sheehan DF, Norkett R, Birsa N, Kittler JT. Miro proteins coordinate microtubule- and actin-dependent mitochondrial transport and distribution. EMBO J 37: 321-336, 2018. doi: 10.15252/embj.201696380.

37. Moore AS, Coscia SM, Simpson CL, Ortega FE, Wait EC, Heddleston JM, Nirschl JJ, Obara CJ, Guedes-Dias P, Boecker CA, Chew T-L, Theriot JA, Lippincott-Schwartz J, Holzbaur ELF. Actin cables and comet tails organize mitochondrial networks in mitosis. Nature 591: 659-664, 2021. doi: 10.1038/s41586-021-03309-5.

38. Scarpulla RC. Nucleus-encoded regulators of mitochondrial function: Integration of respiratory chain expression, nutrient sensing and metabolic stress. Biochim Biophys Acta BBA - Gene Regul Mech 1819: 1088-1097, 2012. doi: 10.1016/j.bbagrm.2011.10.011.

39. Ligon LA, Steward O. Role of microtubules and actin filaments in the movement of mitochondria in the axons and dendrites of cultured hippocampal neurons. .

40. Lovas JR, Wang X. The meaning of mitochondrial movement to a neuron's life. Biochim Biophys Acta - Mol Cell Res 1833: 184-194, 2013. doi: 10.1016/j.bbamcr.2012.04.007.

41. Nguyen TT, Oh SS, Weaver D, Lewandowska A, Maxfield D, Schuler M-H, Smith NK, Macfarlane J, Saunders G, Palmer CA, Debattisti V, Koshiba T, Pulst S, Feldman EL,

Hajnóczky G, Shaw JM. Loss of Miro1-directed mitochondrial movement results in a novel murine 
model for neuron disease. Proc Natl Acad Sci 111: E3631-E3640, 2014.

42. Lin M-Y, Sheng Z-H. Regulation of mitochondrial transport in neurons. Exp Cell Res 334: 35-44, 2015. doi: 10.1016/j.yexcr.2015.01.004.

43. Fransson Å, Ruusala A, Aspenström P. The atypical Rho GTPases Miro-1 and Miro-2 have essential roles in mitochondrial trafficking. Biochem Biophys Res Commun 344: 500-510, 2006. doi: 10.1016/j.bbrc.2006.03.163.

44. Wozniak MJ, Melzer M, Dorner C, Haring H-U, Lammers R. The novel protein KBP regulates mitochondria localization by interaction with a kinesin-like protein. BMC Cell Biol 6: 35, 2005. doi: 10.1186/1471-2121-6-35.

45. Lyons DA, Naylor SG, Mercurio S, Dominguez C, Talbot WS. KBP is essential for axonal structure, outgrowth and maintenance in zebrafish, providing insight into the cellular basis of Goldberg-Shprintzen syndrome. Development 135: 599-608, 2008. doi: 10.1242/dev.012377.

46. Tanaka K, Sugiura Y, Ichishita R, Mihara K, Oka T. KLP6: a newly identified kinesin that regulates the morphology and transport of mitochondria in neuronal cells. J Cell Sci 124: $2457-$ 2465, 2011. doi: 10.1242/jcs.086470.

47. Schnapp BJ, Reese TS. Dynein is the motor for retrograde axonal transport of organelles. Proc Natl Acad Sci 86: 1548-1552, 1989.

48. Asai DJ, Koonce MP. The dynein heavy chain: structure, mechanics and evolution. Trends Cell Biol 11: 196-202, 2001. doi: 10.1016/S0962-8924(01)01970-5.

49. Sheng Z-H, Cai Q. Mitochondrial transport in neurons: impact on synaptic homeostasis and neurodegeneration. Nat Rev Neurosci 13: 77-93, 2012. doi: 10.1038/nrn3156.

50. Schwarzer C, Barnikol-Watanabe S, Thinnes FP, Hilschmann N. Voltage-dependent anion-selective channel (VDAC) interacts with the dynein light chain Tctex 1 and the heat-shock protein PBP74. Int J Biochem Cell Biol 34: 1059-1070, 2002. doi: 10.1016/S1357-2725(02)00026-2.

51. Schroer TA. Dynactin. Annu Rev Cell Dev Biol 20: 759-779, 2004. doi:

10.1146/annurev.cellbio.20.012103.094623.

52. van Spronsen M, Mikhaylova M, Lipka J, Schlager MA, van den Heuvel DJ, Kuijpers M, Wulf PS, Keijzer N, Demmers J, Kapitein LC, Jaarsma D, Gerritsen HC, Akhmanova A, Hoogenraad CC. TRAK/Milton Motor-Adaptor Proteins Steer Mitochondrial Trafficking to Axons and Dendrites. Neuron 77: 485-502, 2013. doi: 10.1016/j.neuron.2012.11.027.

53. Quintero OA, DiVito MM, Adikes RC, Kortan MB, Case LB, Lier AJ, Panaretos NS, Slater SQ, Rengarajan M, Feliu M, Cheney RE. Human Myo19 Is a Novel Myosin that Associates with Mitochondria. Curr Biol 19: 2008-2013, 2009. doi: 10.1016/j.cub.2009.10.026.

54. Rohn JL, Patel JV, Neumann B, Bulkescher J, Mchedlishvili N, McMullan RC, Quintero OA, Ellenberg J, Baum B. Myo19 Ensures Symmetric Partitioning of Mitochondria and Coupling of Mitochondrial Segregation to Cell Division. Curr Biol 24: 2598-2605, 2014. doi: 10.1016/j.cub.2014.09.045.

55. Manor U, Bartholomew S, Golani G, Christenson E, Kozlov M, Higgs H, Spudich J, Lippincott-Schwartz $\mathbf{J}$. A mitochondria-anchored isoform of the actin-nucleating spire protein regulates mitochondrial division. eLife 4: e08828, 2015. doi: 10.7554/eLife.08828.

56. Straub F, Welz T, Alberico H, Brandão RO, Huber A, Samol-Wolf A, Brakebusch C, Woods D, Kollmar M, Martin-Gonzalez J, Kerkhoff E. The SPIRE1 actin nucleator coordinates 
actin/myosin functions in the regulation of mitochondrial motility. .

57. Flannery PJ, Trushina E. Mitochondrial dynamics and transport in Alzheimer's disease.

Mol Cell Neurosci 98: 109-120, 2019. doi: 10.1016/j.mcn.2019.06.009.

58. Vossel KA, Zhang K, Brodbeck J, Daub AC, Sharma P, Finkbeiner S, Cui B, Mucke L. Tau Reduction Prevents A $\beta$-Induced Defects in Axonal Transport. Science 330: 198-198, 2010. doi: 10.1126/science.1194653.

59. Wang X, Su B, Zheng L, Perry G, Smith MA, Zhu X. The role of abnormal mitochondrial dynamics in the pathogenesis of Alzheimer's disease. J Neurochem 109 Suppl 1: 153-159, 2009. doi: 10.1111/j.1471-4159.2009.05867.x.

60. Rui Y, Tiwari P, Xie Z, Zheng JQ. Acute impairment of mitochondrial trafficking by betaamyloid peptides in hippocampal neurons. J Neurosci Off J Soc Neurosci 26: 10480-10487, 2006. doi: 10.1523/JNEUROSCI.3231-06.2006.

61. Stokin GB, Lillo C, Falzone TL, Brusch RG, Rockenstein E, Mount SL, Raman R, Davies P, Masliah E, Williams DS, Goldstein LSB. Axonopathy and Transport Deficits Early in the Pathogenesis of Alzheimer's Disease. Science 307: 1282-1288, 2005. doi: 10.1126/science.1105681.

62. Hsieh CH, Shaltouki A, Gonzalez AE, Bettencourt da Cruz A, Burbulla LF, St.

Lawrence E, Schüle B, Krainc D, Palmer TD, Wang X. Functional Impairment in Miro Degradation and Mitophagy Is a Shared Feature in Familial and Sporadic Parkinson's Disease. Cell Stem Cell 19: 709-724, 2016. doi: 10.1016/j.stem.2016.08.002.

63. Weihofen A, Thomas KJ, Ostaszewski BL, Cookson MR, Selkoe DJ. Pink1 forms a multiprotein complex with Miro and Milton, linking Pink1 function to mitochondrial trafficking. Biochemistry 48: 2045-2052, 2009. doi: 10.1021/bi8019178.

64. Lee H-J, Khoshaghideh F, Lee S, Lee S-J. Impairment of microtubule-dependent trafficking by overexpression of $\alpha$-synuclein. Eur J Neurosci 24: 3153-3162, 2006. doi: 10.1111/j.14609568.2006.05210.x.

65. Yang F, Jiang Q, Zhao J, Ren Y, Sutton MD, Feng J. Parkin Stabilizes Microtubules through Strong Binding Mediated by Three Independent Domains*. J Biol Chem 280: 17154-17162, 2005. doi: 10.1074/jbc.M500843200.

66. Gillardon F. Leucine-rich repeat kinase 2 phosphorylates brain tubulin-beta isoforms and modulates microtubule stability - a point of convergence in Parkinsonian neurodegeneration? $J$ Neurochem 110: 1514-1522, 2009. doi: 10.1111/j.1471-4159.2009.06235.x.

67. Sasaki S, Iwata M. Impairment of fast axonal transport in the proximal axons of anterior horn neurons in amyotrophic lateral sclerosis. Neurology 47: 535-540, 1996. doi: 10.1212/WNL.47.2.535.

68. De Vos KJ, Chapman AL, Tennant ME, Manser C, Tudor EL, Lau K-F, Brownlees J, Ackerley S, Shaw PJ, McLoughlin DM, Shaw CE, Leigh PN, Miller CCJ, Grierson AJ. Familial amyotrophic lateral sclerosis-linked SOD1 mutants perturb fast axonal transport to reduce axonal mitochondria content. Hum Mol Genet 16: 2720-2728, 2007. doi: 10.1093/hmg/ddm226.

69. Magrané J, Hervias I, Henning MS, Damiano M, Kawamata H, Manfredi G. Mutant SOD1 in neuronal mitochondria causes toxicity and mitochondrial dynamics abnormalities. Hum Mol Genet 18: 4552-4564, 2009. doi: 10.1093/hmg/ddp421.

70. Shi P, Ström A-L, Gal J, Zhu H. Effects of ALS-related SOD1 mutants on dynein- and 
KIF5-mediated retrograde and anterograde axonal transport. Biochim Biophys Acta BBA - Mol Basis Dis 1802: 707-716, 2010. doi: 10.1016/j.bbadis.2010.05.008.

71. Rezin GT, Amboni G, Zugno AI, Quevedo J, Streck EL. Mitochondrial Dysfunction and Psychiatric Disorders. Neurochem Res 34: 1021, 2008. doi: 10.1007/s11064-008-9865-8.

72. Flippo KH, Strack S. An emerging role for mitochondrial dynamics in schizophrenia. Schizophr Res 187: 26-32, 2017. doi: 10.1016/j.schres.2017.05.003.

73. Caviston JP, Ross JL, Antony SM, Tokito M, Holzbaur ELF. Huntingtin facilitates dynein/dynactin-mediated vesicle transport. Proc Natl Acad Sci U S A 104: 10045-10050, 2007. doi: 10.1073/pnas.0610628104.

74. Colin E, Zala D, Liot G, Rangone H, Borrell-Pagès M, Li X-J, Saudou F, Humbert S. Huntingtin phosphorylation acts as a molecular switch for anterograde/retrograde transport in neurons. EMBO J 27: 2124-2134, 2008. doi: 10.1038/emboj.2008.133.

75. Trushina E, Dyer RB, Badger JD, Ure D, Eide L, Tran DD, Vrieze BT, LegendreGuillemin V, McPherson PS, Mandavilli BS, Van Houten B, Zeitlin S, McNiven M, Aebersold R, Hayden M, Parisi JE, Seeberg E, Dragatsis I, Doyle K, Bender A, Chacko C, McMurray CT. Mutant huntingtin impairs axonal trafficking in mammalian neurons in vivo and in vitro. Mol Cell Biol 24: 8195-8209, 2004. doi: 10.1128/MCB.24.18.8195-8209.2004.

76. Katajisto P, Döhla J, Chaffer CL, Pentinmikko N, Marjanovic N, Iqbal S, Zoncu R, Chen W, Weinberg RA, Sabatini DM. Asymmetric apportioning of aged mitochondria between daughter cells is required for stemness. Science 348: 340-343, 2015. doi: 10.1126/science.1260384.

77. Hinge A, He J, Bartram J, Javier J, Xu J, Fjellman E, Sesaki H, Li T, Yu J, Wunderlich M, Mulloy J, Kofron M, Salomonis N, Grimes HL, Filippi M-D. Asymmetrically Segregated Mitochondria Provide Cellular Memory of Hematopoietic Stem Cell Replicative History and Drive HSC Attrition. Cell Stem Cell 26: 420-430.e6, 2020. doi: 10.1016/j.stem.2020.01.016.

78. Adams WC, Chen Y-H, Kratchmarov R, Yen B, Nish SA, Lin W-HW, Rothman NJ, Luchsinger LL, Klein U, Busslinger M, Rathmell JC, Snoeck H-W, Reiner SL. AnabolismAssociated Mitochondrial Stasis Driving Lymphocyte Differentiation over Self-Renewal. Cell Rep 17: 3142-3152, 2016. doi: 10.1016/j.celrep.2016.11.065.

79. Ko YH, Lin Z, Flomenberg N, Pestell RG, Howell A, Sotgia F, Lisanti MP, MartinezOutschoorn UE. Glutamine fuels a vicious cycle of autophagy in the tumor stroma and oxidative mitochondrial metabolism in epithelial cancer cells: Implications for preventing chemotherapy resistance. Cancer Biol Ther 12: 1085-1097, 2011. doi: 10.4161/cbt.12.12.18671.

80. Shin MK, Cheong JH. Mitochondria-centric bioenergetic characteristics in cancer stem-like cells. Arch Pharm Res 42: 113-127, 2019. doi: 10.1007/s12272-019-01127-y.

81. Tan AS, Baty JW, Dong LF, Bezawork-Geleta A, Endaya B, Goodwin J, Bajzikova M, Kovarova J, Peterka M, Yan B, Pesdar EA, Sobol M, Filimonenko A, Stuart S, Vondrusova M, Kluckova K, Sachaphibulkij K, Rohlena J, Hozak P, Truksa J, Eccles D, Haupt LM, Griffiths LR, Neuzil J, Berridge M V. Mitochondrial genome acquisition restores respiratory function and tumorigenic potential of cancer cells without mitochondrial DNA. Cell Metab 21: 81-94, 2015. doi: 10.1016/j.cmet.2014.12.003.

82. Spees JL, Olson SD, Whitney MJ, Prockop DJ. Mitochondrial transfer between cells can rescue aerobic respiration. Proc Natl Acad Sci U S A 103: 1283-1288, 2006. doi: 10.1073/pnas.0510511103. 
83. Cho YM, Kim JH, Kim M, Park SJ, Koh SH, Ahn HS, Kang GH, Lee J Bin, Park KS, Lee HK. Mesenchymal stem cells transfer mitochondria to the cells with virtually no mitochondrial function but not with pathogenic mtDNA mutations. PLOS ONE 7: 0-7, 2012. doi: 10.1371/journal.pone.0032778.

84. Li X, Zhang Y, Yeung SC, Liang Y, Liang X, Ding Y, Ip MSM, Tse HF, Mak JCW, Lian Q. Mitochondrial transfer of induced pluripotent stem cell-derived mesenchymal stem cells to airway epithelial cells attenuates cigarette smoke-induced damage. Am J Respir Cell Mol Biol 51: 455-465, 2014. doi: $10.1165 / \mathrm{rcmb} .2013-05290 \mathrm{OC}$.

85. Liu K, Ji K, Guo L, Wu W, Lu H, Shan P, Yan C. Mesenchymal stem cells rescue injured endothelial cells in an in vitro ischemia-reperfusion model via tunneling nanotube like structuremediated mitochondrial transfer. Microvasc Res 92: 10-18, 2014. doi: 10.1016/j.mvr.2014.01.008.

86. Cowan DB, Yao R, Akurathi V, Snay ER, Thedsanamoorthy JK, Zurakowski D, Ericsson M, Friehs I, Wu Y, Levitsky S, Del Nido PJ, Packard AB, McCully JD. Intracoronary delivery of mitochondria to the ischemic heart for cardioprotection. PLOS ONE 11: 1-19, 2016. doi: 10.1371/journal.pone.0160889.

87. Lin TK, Chen S Der, Chuang YC, Lan MY, Chuang JH, Wang PW, Hsu TY, Wang FS, Tsai MH, Huang ST, Wang XW, Tsai PC, Lin HY, Liou CW. Mitochondrial transfer of wharton's jelly mesenchymal stem cells eliminates mutation burden and rescues mitochondrial bioenergetics in rotenone-stressed MELAS fibroblasts. Oxid Med Cell Longev 2019, 2019. doi:

$10.1155 / 2019 / 9537504$.

88. Hayakawa K, Esposito E, Wang X, Terasaki Y, Liu Y, Xing C, Ji X, Lo EH. Transfer of mitochondria from astrocytes to neurons after stroke. Nature 535: 551-555, 2016. doi: 10.1038/nature18928.

89. Pasquier J, Guerrouahen BS, Ghiabi P, Maleki M, Al Sulaiti H, Le Foll F, Rafii A. Tunneling nanotubes mediate preferential transfer of mitochondria from endothelial to cancer cells and confer chemoresistance. Qatar Found Annu Res Forum Proc : BMP88, 2012. doi: 10.5339/qfarf.2012.bmp88.

90. Moschoi R, Imbert V, Nebout M, Chiche J, Mary D, Prebet T, Saland E, Castellano R, Pouyet L, Collette Y, Vey N, Chabannon C, Recher C, Sarry JE, Alcor D, Peyron JF, Griessinger E. Protective mitochondrial transfer from bone marrow stromal cells to acute myeloid leukemic cells during chemotherapy. Blood 128: 253-264, 2016. doi: 10.1182/blood-2015-07655860 .

91. Lu J, Zheng X, Li F, Yu Y, Chen Z, Liu Z, Wang Z, Xu H, Yang W. Tunneling nanotubes promote intercellular mitochondria transfer followed by increased invasiveness in bladder cancer cells. Oncotarget 8: 15539-15552, 2017. doi: 10.18632/oncotarget.14695.

92. Shachar I, Karin N. The dual roles of inflammatory cytokines and chemokines in the regulation of autoimmune diseases and their clinical implications. J Leukoc Biol 93: 51-61, 2013. doi: 10.1189/jlb.0612293.

93. D'ambrosio D, Mariani M, Panina-Bordignon P, Sinigaglia F. Chemokines and Their Receptors Guiding T Lymphocyte Recruitment in Lung Inflammation. Am J Respir Crit Care Med 164: 1266-1275, 2001. doi: 10.1164/ajrccm.164.7.2103011.

94. Campello S, Lacalle RA, Bettella M, Mañes S, Scorrano L, Viola A. Orchestration of lymphocyte chemotaxis by mitochondrial dynamics. J Exp Med 203: 2879-2886, 2006. doi: 10.1084/jem.20061877. 
95. Seyfried TN, Huysentruyt LC. On the Origin of Cancer Metastasis. Crit Rev Oncog 18, 2013. doi: 10.1615/CritRevOncog.v18.i1-2.40.

96. Ong MS, Deng S, Halim CE, Cai W, Tan TZ, Huang RY-J, Sethi G, Hooi SC, Kumar AP, Yap CT. Cytoskeletal Proteins in Cancer and Intracellular Stress: A Therapeutic Perspective. Cancers 12, 2020. doi: 10.3390/cancers12010238.

97. Ali MRK, Wu Y, Tang Y, Xiao H, Chen K, Han T, Fang N, Wu R, El-Sayed MA. Targeting cancer cell integrins using gold nanorods in photothermal therapy inhibits migration through affecting cytoskeletal proteins. Proc Natl Acad Sci 114: E5655-E5663, 2017.

98. Stehn JR, Haass NK, Bonello T, Desouza M, Kottyan G, Treutlein H, Zeng J, Nascimento PRBB, Sequeira VB, Butler TL, Allanson M, Fath T, Hill TA, McCluskey A, Schevzov G, Palmer SJ, Hardeman EC, Winlaw D, Reeve VE, Dixon I, Weninger W, Cripe TP, Gunning PW. A Novel Class of Anticancer Compounds Targets the Actin Cytoskeleton in Tumor Cells. Cancer Res 73: 5169-5182, 2013.

99. Desai SP, Bhatia SN, Toner M, Irimia D. Mitochondrial localization and the persistent migration of epithelial cancer cells. Biophys $J$ 104: 2077-2088, 2013. doi: 10.1016/j.bpj.2013.03.025.

100. Safiulina D, Kuum M, Choubey V, Hickey MA, Kaasik A. Mitochondrial transport proteins RHOT1 and RHOT2 serve as docking sites for PRKN-mediated mitophagy. Autophagy 15: 930-931, 2019. doi: 10.1080/15548627.2019.1586260.

101. Nakatogawa H, Suzuki K, Kamada Y, Ohsumi Y. Dynamics and diversity in autophagy mechanisms: lessons from yeast. Nat Rev Mol Cell Biol 10: 458-467, 2009. doi: 10.1038/nrm2708.

102. Youle RJ, Narendra DP. Mechanisms of mitophagy. Nat Rev Mol Cell Biol 12: 9-14, 2011. doi: $10.1038 / \mathrm{nrm} 3028$.

103. Schieke SM, McCoy JP, Finkel T. Coordination of mitochondrial bioenergetics with G1 phase cell cycle progression. Cell Cycle 7: 1782-1787, 2008. doi: 10.4161/cc.7.12.6067.

104. Owusu-Ansah E, Yavari A, Mandal S, Banerjee U. Distinct mitochondrial retrograde signals control the G1-S cell cycle checkpoint. Nat Genet 40: 356-361, 2008. doi: 10.1038/ng.2007.50.

105. Sarraf SA, Sideris DP, Giagtzoglou N, Ni L, Kankel MW, Sen A, Bochicchio LE, Huang C-H, Nussenzweig SC, Worley SH, Morton PD, Artavanis-Tsakonas S, Youle RJ, Pickrell AM. PINK1/Parkin Influences Cell Cycle by Sequestering TBK1 at Damaged Mitochondria, Inhibiting Mitosis. Cell Rep 29: 225-235.e5, 2019. doi: 10.1016/j.celrep.2019.08.085.

106. Palis J. Primitive and definitive erythropoiesis in mammals. Front Physiol 5, 2014. doi: 10.3389/fphys.2014.00003.

107. Moras M, Lefevre SD, Ostuni MA. From Erythroblasts to Mature Red Blood Cells: Organelle Clearance in Mammals. Front Physiol 8, 2017. doi: 10.3389/fphys.2017.01076.

108. Schweers RL, Zhang J, Randall MS, Loyd MR, Li W, Dorsey FC, Kundu M, Opferman JT, Cleveland JL, Miller JL, Ney PA. NIX is required for programmed mitochondrial clearance during reticulocyte maturation. Proc Natl Acad Sci U S A 104: 19500-19505, 2007. doi: 10.1073/pnas.0708818104.

109. Mortensen M, Ferguson DJP, Edelmann M, Kessler B, Morten KJ, Komatsu M, Simon AK. Loss of autophagy in erythroid cells leads to defective removal of mitochondria and severe anemia in vivo. Proc Natl Acad Sci U S A 107: 832-837, 2010. doi: 10.1073/pnas.0913170107. 
110. Sandoval H, Thiagarajan P, Dasgupta SK, Schumacher A, Prchal JT, Chen M, Wang J. Essential role for Nix in autophagic maturation of erythroid cells. Nature 454: 232-235, 2008. doi: 10.1038/nature07006.

111. Novak I, Kirkin V, McEwan DG, Zhang J, Wild P, Rozenknop A, Rogov V, Löhr F, Popovic D, Occhipinti A, Reichert AS, Terzic J, Dötsch V, Ney PA, Dikic I. Nix is a selective autophagy receptor for mitochondrial clearance. EMBO Rep 11: 45-51, 2010. doi: 10.1038/embor.2009.256.

112. Kundu M, Lindsten T, Yang C-Y, Wu J, Zhao F, Zhang J, Selak MA, Ney PA, Thompson CB. Ulk1 plays a critical role in the autophagic clearance of mitochondria and ribosomes during reticulocyte maturation. Blood 112: 1493-1502, 2008. doi: 10.1182/blood-2008-02-137398.

113. Zhu H, Foretz M, Xie Z, Zhang M, Zhu Z, Xing J, Leclerc J, Gaudry M, Viollet B, Zou M-H. PRKAA1/AMPK $\alpha 1$ is required for autophagy-dependent mitochondrial clearance during erythrocyte maturation. Autophagy 10: 1522-1534, 2014. doi: 10.4161/auto.29197.

114. Zhang J, Randall MS, Loyd MR, Dorsey FC, Kundu M, Cleveland JL, Ney PA. Mitochondrial clearance is regulated by Atg7-dependent and -independent mechanisms during reticulocyte maturation. Blood 114: 157-164, 2009. doi: 10.1182/blood-2008-04-151639.

115. Nishida Y, Arakawa S, Fujitani K, Yamaguchi H, Mizuta T, Kanaseki T, Komatsu M, Otsu K, Tsujimoto Y, Shimizu S. Discovery of Atg5/Atg7-independent alternative macroautophagy. Nature 461: 654-658, 2009. doi: 10.1038/nature08455.

116. Stenmark H. Rab GTPases as coordinators of vesicle traffic. Nat Rev Mol Cell Biol 10: 513525, 2009. doi: 10.1038/nrm2728.

117. Wang J, Fang Y, Yan L, Yuan N, Zhang S, Xu L, Nie M, Zhang X, Wang J. Erythroleukemia cells acquire an alternative mitophagy capability. Sci Rep 6: 24641, 2016. doi: 10.1038/srep24641.

118. Jiang H, Yang L, Guo L, Cui N, Zhang G, Liu C, Xing L, Shao Z, Wang H. Impaired Mitophagy of Nucleated Erythroid Cells Leads to Anemia in Patients with Myelodysplastic Syndromes. Oxid Med Cell Longev 2018: e6328051, 2018. doi: 10.1155/2018/6328051.

119. Martino S, Arlet J-B, Odièvre M-H, Jullien V, Moras M, Hattab C, Lefebvre T, Gouya L, Ostuni MA, Lefevre SD, Kim CLV. Deficient mitophagy pathways in sickle cell disease. $\mathrm{Br} J$ Haematol n/a, [date unknown]. doi: https://doi.org/10.1111/bjh.17416.

120. Ho TT, Warr MR, Adelman ER, Lansinger OM, Flach J, Verovskaya EV, Figueroa ME, Passegué E. Autophagy maintains the metabolism and function of young and old stem cells. Nature 543: 205-210, 2017. doi: 10.1038/nature21388.

121. Ito K, Suda T. Metabolic requirements for the maintenance of self-renewing stem cells. Nat Rev Mol Cell Biol 15: 243-256, 2014. doi: 10.1038/nrm3772.

122. Khacho M, Slack RS. Mitochondrial activity in the regulation of stem cell self-renewal and differentiation. Curr Opin Cell Biol 49: 1-8, 2017. doi: 10.1016/j.ceb.2017.11.003.

123. Ito K, Turcotte R, Cui J, Zimmerman SE, Pinho S, Mizoguchi T, Arai F, Runnels JM, Alt C, Teruya-Feldstein J, Mar JC, Singh R, Suda T, Lin CP, Frenette PS, Ito K. Self-renewal of a purified Tie2+ hematopoietic stem cell population relies on mitochondrial clearance. Science 354: 1156-1160, 2016. doi: 10.1126/science.aaf5530.

124. Vazquez-Martin A, Van den Haute C, Cufí S, Corominas-Faja B, Cuyàs E, Lopez-Bonet 
E, Rodriguez-Gallego E, Fernández-Arroyo S, Joven J, Baekelandt V, Menendez JA.

Mitophagy-driven mitochondrial rejuvenation regulates stem cell fate. Aging 8: 1330-1352, 2016. doi: 10.18632/aging.100976.

125. Xiang G, Yang L, Long Q, Chen K, Tang H, Wu Y, Liu Z, Zhou Y, Qi J, Zheng L, Liu W, Ying Z, Fan W, Shi H, Li H, Lin X, Gao M, Liu J, Bao F, Li L, Duan L, Li M, Liu X.

BNIP3L-dependent mitophagy accounts for mitochondrial clearance during 3 factors-induced somatic cell reprogramming. Autophagy 13: 1543-1555, 2017. doi: 10.1080/15548627.2017.1338545.

126. Esteban-Martínez L, Sierra-Filardi E, McGreal RS, Salazar-Roa M, Mariño G, Seco E, Durand S, Enot D, Graña O, Malumbres M, Cvekl A, Cuervo AM, Kroemer G, Boya P. Programmed mitophagy is essential for the glycolytic switch during cell differentiation. EMBO J 36: 1688-1706, 2017. doi: 10.15252/embj.201695916.

127. Sin J, Andres AM, Taylor DJR, Weston T, Hiraumi Y, Stotland A, Kim BJ, Huang C, Doran KS, Gottlieb RA. Mitophagy is required for mitochondrial biogenesis and myogenic differentiation of C2C12 myoblasts. Autophagy 12: 369-380, 2016. doi: 10.1080/15548627.2015.1115172.

128. Ankel-Simons F, Cummins JM. Misconceptions about mitochondria and mammalian fertilization: Implications for theories on human evolution. Proc Natl Acad Sci U S A 93: 1385913863, 1996.

129. Cummins JM, Wakayama T, Yanagimachi R. Fate of microinjected spermatid mitochondria in the mouse oocyte and embryo. Zygote 6: 213-222, 1998. doi: 10.1017/S0967199498000148.

130. Sato M, Sato K. Degradation of Paternal Mitochondria by Fertilization-Triggered Autophagy in C. elegans Embryos. Science 334: 1141-1144, 2011. doi: 10.1126/science.1210333.

131. Rawi SA, Louvet-Vallée S, Djeddi A, Sachse M, Culetto E, Hajjar C, Boyd L, Legouis R, Galy V. Postfertilization Autophagy of Sperm Organelles Prevents Paternal Mitochondrial DNA Transmission. Science 334: 1144-1147, 2011. doi: 10.1126/science.1211878.

132. Sutovsky P, Moreno RD, Ramalho-Santos J, Dominko T, Simerly C, Schatten G. Ubiquitin tag for sperm mitochondria. Nature 402: 371-372, 1999. doi: 10.1038/46466.

133. Politi Y, Gal L, Kalifa Y, Ravid L, Elazar Z, Arama E. Paternal Mitochondrial Destruction after Fertilization Is Mediated by a Common Endocytic and Autophagic Pathway in Drosophila. Dev Cell 29: 305-320, 2014. doi: 10.1016/j.devcel.2014.04.005.

134. Vadlamudi RK, Joung I, Strominger JL, Shin J. p62, a phosphotyrosine-independent ligand of the $\mathrm{SH} 2$ domain of p561ck, belongs to a new class of ubiquitin-binding proteins. $J$ Biol Chem 271: 20235-20237, 1996. doi: 10.1074/jbc.271.34.20235.

135. Rojansky R, Cha M-Y, Chan DC. Elimination of paternal mitochondria in mouse embryos occurs through autophagic degradation dependent on PARKIN and MUL1. eLife 5, 2016. doi: 10.7554/eLife.17896.

136. Wei Y, Chiang W-C, Sumpter R, Mishra P, Levine B. Prohibitin 2 Is an Inner Mitochondrial Membrane Mitophagy Receptor. Cell 168: 224-238.e10, 2017. doi: 10.1016/j.cell.2016.11.042.

137. Wang Y, Zhang Y, Chen L, Liang Q, Yin X-M, Miao L, Kang B-H, Xue D. Kinetics and specificity of paternal mitochondrial elimination in Caenorhabditis elegans. Nat Commun 7: 12569, 2016. doi: $10.1038 /$ ncomms 12569 . 
138. Guerroué FL, Eck F, Jung J, Starzetz T, Mittelbronn M, Kaulich M, Behrends C.

Autophagosomal Content Profiling Reveals an LC3C-Dependent Piecemeal Mitophagy Pathway. Mol Cell 68: 786-796.e6, 2017. doi: 10.1016/j.molcel.2017.10.029.

139. Abudu YP, Shrestha BK, Zhang W, Palara A, Brenne HB, Larsen KB, Wolfson DL, Dumitriu G, Øie CI, Ahluwalia BS, Levy G, Behrends C, Tooze SA, Mouilleron S, Lamark T, Johansen T. SAMM50 acts with p62 in piecemeal basal- and OXPHOS-induced mitophagy of SAM and MICOS components. J Cell Biol 220, 2021. doi: 10.1083/jcb.202009092. 